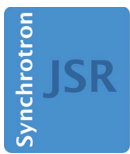

JOURNAL OF

SYNCHROTRON

RADIATION

ISSN 1600-5775

\section{Implementation of cryogenic tender X-ray HR-XANES spectroscopy at the ACT station of the CAT-ACT beamline at the KIT Light Source}

Bianca Schacherl, Tim Prüssmann, Kathy Dardenne, Kirsten Hardock, Volker Krepper, Jörg Rothe,* Tonya Vitova* and Horst Geckeis

Institute for Nuclear Waste Disposal (INE), Karlsruhe Institute of Technology (KIT), Hermann-von-Helmholtz-Platz 1, 76344 Eggenstein-Leopoldshafen, Germany. *Correspondence e-mail: joerg.rothe@kit.edu, tonya.vitova@kit.edu

The ACT experimental station of the CAT-ACT wiggler beamline at the Karlsruhe Institute of Technology (KIT) Light Source is dedicated to the investigation of radionuclide materials with radioactivities up to 1000000 times the exemption limit by various speciation techniques applying monochromatic $\mathrm{X}$-rays. In this article, the latest technological developments at the ACT station that enable high-resolution X-ray absorption near-edge structure (HR-XANES) spectroscopy for low radionuclide loading samples are highlighted - encompassing the investigation of actinide elements down to 1 p.p.m. concentration combined with a cryogenic sample environment reducing beam-induced sample alterations. One important part of this development is a versatile gas tight plexiglass encasement ensuring that all beam paths in the five-analyzer-crystal Johann-type X-ray emission spectrometer run within He atmosphere. The setup enables the easy exchange between different experiments (conventional X-ray absorption fine structure, HR-XANES, high-energy or wide-angle X-ray scattering, tender to hard X-ray spectroscopy) and opens up the possibility for the investigation of environmental samples, such as specimens containing transuranium elements from contaminated land sites or samples from sorption and diffusion experiments to mimic the far field of a breached nuclear waste repository.

\section{Introduction}

Synchrotron radiation based speciation methods for radioactive samples are often limited to dedicated beamline endstations due to the strict safety and radiation protection regulations for handling radionuclide materials at light sources (Scheinost et al., 2021). Two of those few endstations - the INE-Beamline and the ACT station at the Karlsruhe Institute of Technology (KIT) Light Source (Rothe et al., 2012; Zimina et al., 2017) - are operated by KIT-INE (the Institute for Nuclear Waste Disposal at KIT). However, some synchrotron facilities accept proposals to investigate radioactive materials on conventional beamlines if the radionuclide activities stay below the exemption limit. Others temporarily upgrade the safety status of selected endstations to allow for radionuclide research up to a certain extent - generally excluding highly radioactive materials like spent nuclear fuel or certain isotopes. During the past decade, high (energy) resolution $\mathrm{X}$-ray absorption near-edge structure (HR-XANES) spectroscopy - also called high-energy-resolution fluorescencedetected X-ray absorption near-edge structure (HERFDXANES) - has proven to be a highly valuable tool for the oxidation state determination of actinides (An). However, in this case, on the one hand the inefficient detection process 
requires high photon fluxes (where samples might be prone to beam-induced alterations) and rather high analyte concentrations. On the other hand, it is necessary to find a trade-off between necessary sample containment and radiation safety precautions at synchrotron radiation facilities and sufficiently transparent X-ray windows. Hence, already for investigations at the moderately high X-ray energies corresponding to the An $L_{3}$ absorption edges (Th-Es: $\sim 16.3-20.4 \mathrm{keV}$ ), HRXANES investigations of actinides are experimentally highly demanding. This applies all the more in the 'tender' X-ray regime below $\sim 4.5 \mathrm{keV}$, where the corresponding An $M$ absorption edges are probed. It is for this reason, for example, that HR-XANES data for the $L$ - and $M$-level absorption edges of transuranium elements within the An family basically stem from only a few X-ray emission spectrometers at four synchrotron light sources worldwide.

While reports of transuranium experiments are generally scarce, we want to mention several beamlines that have started to develop their capabilities towards $L_{3}$-edge $\mathrm{X}$-ray emission spectroscopy experiments of various uranium or thorium samples. Pioneering work was carried out for intermetallic $\mathrm{U}$ compounds by Rueff et al. (2007) at ID16, and for U oxide compounds by us and collaborators at ID26 of the European Synchrotron Radiation Facility (ESRF) (Vitova et al., 2010) and at the INE-Beamline, KIT Light Source [Karlsruhe Research Accelerator (KARA) storage ring] (Walshe et al., 2014). Different types of three-analyzer-crystal X-ray emission spectrometers were used for $\mathrm{U}_{L_{3}}$-edge studies at BL39XU at SPring-8 (Kawamura et al., 2020; Honda et al., 2020) and at beamline ID20 at Diamond Light Source (Pan et al., 2020), and for Th $L_{3}$-edge experiments at BL14W1 at the Shanghai Synchrotron Radiation Facility (SSRF) (Bao et al., 2018; Duan, Bao et al., 2017; Duan, Gu et al., 2017). The microXAS beamline at the Swiss Light Source (SLS) started experiments with high spatial resolution $(1 \mu \mathrm{m})$ using an emission spectrometer with cylindrical von Hamos geometry (Szlachetko et al., 2012) at the $\mathrm{U} L_{3}$-edge (Grolimund, 2021). Moreover, a portable single-analyzer-crystal X-ray emission spectrometer was used at BL11-2 at the Stanford Synchrotron Radiation Laboratory (SSRL) to obtain $\mathrm{U} L_{3}$-edge $\mathrm{X}$-ray emission spectroscopy data (Ditter et al., 2020).

Concerning transuranium elements, early work has been performed at the high-resolution X-ray emission spectrometer (HR-XES) at beamline ID16 of the ESRF, where already in $2010 \mathrm{Am} L_{3}$-edge resonant inelastic X-ray scattering (RIXS) data were recorded (Heathman et al., 2010). Another beamline facility equipped to temporarily perform radionuclide work is beamline 6-2 at the SSRL. Here, a seven-analyzercrystal Johann-type X-ray emission spectrometer with $1 \mathrm{~m}$ bending radius was used, e.g. to study the $\mathrm{Pu} L_{3}$-edge of intermetallic plutonium phases (Booth et al., 2012, 2014), $\mathrm{PuO}_{2}$ (Tobin \& Shuh, 2015) and the $\mathrm{Np} L_{3}$-edge for $\mathrm{NpSe}_{2}$ solid phases (Jin et al., 2019). Popa et al. (2015) analyzed the structure of $\mathrm{Pu}(\mathrm{III})$ phosphate, applying the Johann-type $\mathrm{X}$-ray emission spectrometer at the MARS beamline at SOLEIL for Pu and Am $L_{3}$ HR-XANES measurements, and herewith confirming the +3 valence state of $\mathrm{Pu}$ as well as that of its Am daughter resulting from $\beta^{-}$decay. At the INEBeamline in 2014, in a collaborative project with the Joint Research Center Karlsruhe, we investigated the oxidation states of $\mathrm{Pu}$ at the $\mathrm{Pu} L_{3}$-edge in a study exploring the phase diagram of $\mathrm{UO}_{2}-\mathrm{PuO}_{2}$ at high temperatures (Böhler et al., 2014) and for Pu oxide nanocrystals (Hudry et al., 2014).

A large increase in sensitivity to differences in the electronic structure unfolds for HR-XANES spectroscopy at the An $M_{4,5}$-edges (Butorin et al., 1996; Rothe et al., 2012; Kvashnina et al., 2013; Vitova et al., 2013). Difficulties arise because the corresponding absorption and emission energies between $\sim 3$ and $4.5 \mathrm{keV}$ belong to the tender $\mathrm{X}$-ray region. At these energies, air molecules as well as containment materials strongly scatter and/or absorb the X-rays [incident beam impinging onto the sample, X-ray fluorescence/inelastically scattered radiation emitted by the sample, and monochromated radiation diffracted and focused by the analyzer crystal(s) onto the detector]. For this reason, a specific adaption of the experimental stages, such as He-filled bags bridging the air gap between sample, crystal(s) and detector, an $\mathrm{He}$ encasement enclosing the whole spectrometer or even vacuum conditions, is required to enable efficient X-ray emission spectroscopy. Up to now, this has limited the reported $M$-edge studies of transuranium elements to only four beamlines worldwide. At the KIT Light Source a five-analyzer-crystal Johann-type X-ray emission spectrometer based on an original ID26 design was initially commissioned and successfully tested at the INE-Beamline for radionuclide research (Prüßmann, 2016; Vitova et al., 2017; Bahl et al., 2017; Popa et al., 2016; Rothe et al., 2012), and was later on transferred to the ACT station of the new CAT-ACT wiggler beamline after completion of the endstations in 2016 (Zimina et al., 2017; Rothe et al., 2019). With this spectrometer a large contribution to the development of the $M$-edge spectroscopy for the transuranium elements was achieved, e.g. the first-ever measured $\mathrm{Pu} M_{5}$-edge XANES/HR-XANES (Rothe et al., 2012) was already published in 2012. Later on, the first $\mathrm{Pu}$ and $\mathrm{Np} \mathrm{M}_{5^{-}}$ edge HR-XANES and $3 d 4 f$ RIXS (Vitova et al., 2017) and various $\mathrm{Np}, \mathrm{Pu}, \mathrm{Am}$ and $\mathrm{U} M$-edge HR-XANES spectra were recorded (Vitova et al., 2017, 2020; Bahl et al., 2017; Epifano et $a l ., 2019)$. At the MARS beamline of the SOLEIL synchrotron - belonging to the few dedicated synchrotron radiation stations for the investigation of nuclear materials including waste forms - an He-filled bag between the sample position, a single analyzer crystal with $1 \mathrm{~m}$ bending radius in Johann geometry and the detector can be used to reduce absorption in air. With this setup, $\mathrm{Pu} M_{4}$-edge HR-XANES/RIXS experiments on plutonium carbonate samples (Pidchenko et al., 2020), $\mathrm{PuO}_{2}$ phases (Gerber et al., 2020) and uranium compounds were performed (Hunault et al., 2019). At beamline ID26 of the ESRF a five-analyzer-crystal Johann-type $\mathrm{X}$-ray emission spectrometer with $1 \mathrm{~m}$ bending radius was employed to record, for example, the $\mathrm{Pu} M_{4}$-edge of plutonium nanoparticles (Gerber et al., 2020; Kvashnina et al., 2019). A similar spectrometer is meanwhile situated at the ESRF Rossendorf beamline (BM20 ROBL), another dedicated beamline for radionuclide research. Although only $L_{3^{-}}$ 
edge data of $\mathrm{Pu}, \mathrm{U}$ and $\mathrm{Th}$ have been published so far (Amidani et al., 2021; Gerber et al., 2020), the whole spectrometer can be placed inside a bag filled with He to record edges at tender energies.

Besides applying crystal spectrometers in the tender to hard $\mathrm{X}$-ray spectral range, a few beamlines worldwide took provisions for high-resolution An spectroscopy research in the soft $\mathrm{X}$-ray to vacuum ultraviolet range, giving access to shallower absorption edges - with naturally narrow line widths - at the An $N$ or $O$ levels (or the core levels of low- $Z$ ligand atoms) or to hard $\mathrm{X}$-ray inelastic scattering with $\mathrm{meV}$ resolution range, enabling the detection of specific X-ray photon-phonon interactions, i.e. accessing basic solid-state properties such as superconductivity in solid-state An materials. In the former research area, pioneering An spectromicroscopy work employing the soft X-ray scanning transmission X-ray microscopy endstation at Advanced Light Source (ALS) beamline 11.0.2 (Lawrence Berkeley National Laboratory) has been reported (Dalodière et al., 2017). Scientists employing ALS beamline 7.0.1's soft X-ray absorption and resonant scattering capabilities have provided, for example, $\mathrm{Pu} N_{6,7}$-edge XANES data as well as $\mathrm{NpO}_{2}$ RIXS at the Np $O_{5}$-edge $(\sim 100 \mathrm{eV})(c f$. Modin et al., 2011; Tobin et al., 2002; Butorin et al., 2013, 2016). Feasibility of experiments in the latter field has been demonstrated, for example, in $\mathrm{Pu}$ metal/ $\mathrm{PuO}_{2}$ scattering experiments at the Advanced Photon Source (APS) beamline 30-ID-B,C (HERIX endstation, Argonne National Laboratory), offering momentum-resolved inelastic X-ray scattering with high resolution ( $\sim 1.5 \mathrm{meV})$ (Manley et al., 2009, 2012).

Almost all of the reported HR-XES studies work with relatively high An concentrations. This, however, often prevents studies of environmental samples from contaminated land sites or sorption and diffusion samples from experiments in the context of safety case studies in nuclear waste disposal research, where loadings of actinides below the p.p.m. range should prevail. In this article, we present the technical developments at the ACT station towards enabeling those low An loading HR-XANES experiments while still having the flexibility for other experimental techniques such as conventional high-energy X-ray absorption fine structure (XAFS) in transmission or total fluorescence-yield detection mode and Laue-type high-energy or wide-angle X-ray scattering (HEXS/ WAXS) up to $\sim 55 \mathrm{keV}$ photon energy.

As aforementioned, another important point is sample integrity upon irradiation conditions at highly brilliant synchrotron radiation sources. Different types of beaminduced alterations are observed at ambient conditions, especially for often redox-labile An specimens (Wilk et al., 2005; Denecke et al., 2005). These photo-oxidations or photoreductions mostly occur for aqueous systems or hydrated pastes and, thus, are especially relevant for environmental samples. Beam-induced changes need to be thoroughly monitored and excluded at the utmost degree to obtain unbiased speciation information. One possibility to exclude those changes is cooling the samples below $180 \mathrm{~K}$ (Göttlicher et al., 2018). From screening the relevant literature, to the best of our knowledge, all 'photon hungry' HR-XANES/XES experiments on transuranium elements up to now have been performed at room temperature. In Section 3 we will present the development of a cryogenic sample holder for radioactive samples adapted to a commercial liquid $\mathrm{N}_{2} / \mathrm{He}$ cryostat. Here the challenge was to design and approve a system for double encapsulation featuring sufficiently X-ray transparent windows for spectroscopy in the tender X-ray region while at the same time - withstanding thermal-isolation vacuum conditions.

\section{INE beamline facilities at the KIT Light Source}

INE at KIT (KIT-INE) operates two experimental stations dedicated to the investigation of radionuclide materials by X-ray based methods at KARA (former ANKA synchrotron light source) - the INE-Beamline at a bending magnet port (fully operational since 2005) and the ACT laboratory at the CAT-ACT wiggler beamline (commissioned in 2016) (Rothe et al., 2012, 2019; Zimina et al., 2017). Both beamline hutches are equipped and licensed to investigate radioisotopes up to activities equal to $10^{6}$ times the (European) exemption limits and $200 \mathrm{mg}$ for the fissile isotopes ${ }^{235} \mathrm{U}$ or ${ }^{239} \mathrm{Pu}$ (the exemption limits are generally $10^{3}$ or $10^{4} \mathrm{~Bq}$ for most relevant radionuclides under investigation at these beamlines). They are permanently designated as monitored areas for handling radioactive materials. Their status can be upgraded to temporary controlled areas whenever radionuclide inventories exceed the exemption limits (applying a sum rule in the presence of multiple isotopes). The license at both stations enables the investigation of 'hot' materials including genuine nuclear-waste forms as well as in situ investigations at nonambient conditions (e.g. high $p$ and/or high $T$ ) of radionuclides within a double containment. The beamline concept benefits from the flexibility of evaluating and approving new experimental setups by INE's own technical commission, ensuring adherence to safety regulations while at the same time avoiding the limitation of experiments by standardized sample containments or an $\alpha$-box environment. The focus at both beamlines has been originally placed on XAFS-based speciation investigations in the context of the nuclear-wastedisposal safety case (encompassing processes during interim storage of spent nuclear fuel or nuclear-waste glass and final deep geological disposal of these materials). More recently, another emphasis has been placed on fundamental An studies exploiting the capabilities of HR-XES techniques within the basic KIT/Helmholtz research (NUSAFE program topic) or third-party-funded projects such as the European Research Council (ERC) Consolidator grant 'THE ACTINIDE BOND properties in solid, liquid and gas state'.

\section{Recent upgrades at the ACT station}

The Johann-type X-ray emission spectrometer at the ACT laboratory is routinely applied for HR-XES/HR-XANES and RIXS experiments in a broad energy range encompassing the An $M$ - and $L$-edges (Th-Es feasible). Several analyzer-crystal sets [five each of $\mathrm{Si}(111), \mathrm{Si}(110)$ and $\mathrm{Ge}(111)$, and four each 
of $\mathrm{Ge}(220)$ and $\mathrm{Ge}(311)$, Saint-Gobain, France] with a bending radius of $1 \mathrm{~m}$ are available to cover the relevant absorption levels. The tender X-ray range at ACT is accessible with an $\mathrm{Si}\langle 111\rangle$ crystal pair in the cryo-cooled double-crystal monochromator (DCM) down to $\sim 3.4 \mathrm{keV}$ [ $c f$. Zimina et al. (2017) for details]. The beam is focused by a toroidal Si mirror, resulting in a spot size of $\sim 1 \mathrm{~mm} \times 1 \mathrm{~mm}$. The photon flux between 3.6 and $4 \mathrm{keV}$ shown in Fig. 1 has been precisely determined using a short ionization chamber (Oken, Japan, model S-1329A1 with 33 mm electrode length) filled with $\mathrm{N}_{2}$ at ambient pressure. In the tender X-ray region, scattering and absorption of X-rays is efficiently minimized by enclosing all beam paths - i.e. that of the impinging beam and those between the sample, the analyzer crystals and the single-diode silicon-drift-detector entrance window (KETEK VITUS SDD, Germany) arranged in a vertical Rowland circle geometry - in He atmosphere. A rigid plexiglass box housing the spectrometer components has been designed and recently installed on the ACT breadboard table (Fig. 2). The improved design allows one to keep stable conditions with less than 150 p.p.m. oxygen inside the box through a controlled He flow of $\sim 51 \mathrm{~min}^{-1}$. The five crystal holders are placed inside a flexible polyvinyl chloride (PVC) bag clamped by the five crystal mounts and spanned by an oriel protruding from the left-hand side wall (in beam direction) of the He box. This setup allows for sufficient freedom of motion of the crystals along their individual Rowland circles. The He box is equipped with a spacious rectangular lock chamber for exchanging sample cells (e.g. in situ cells or combined UV-Vis/XES setups) and a panel at the back side (in beam direction) providing various media and power feedthroughs (e.g. $\mathrm{He} / \mathrm{N}_{2} / \mathrm{Ar}$ inert gas supply, cooling water, motor power/encoder/limit-switch lines,

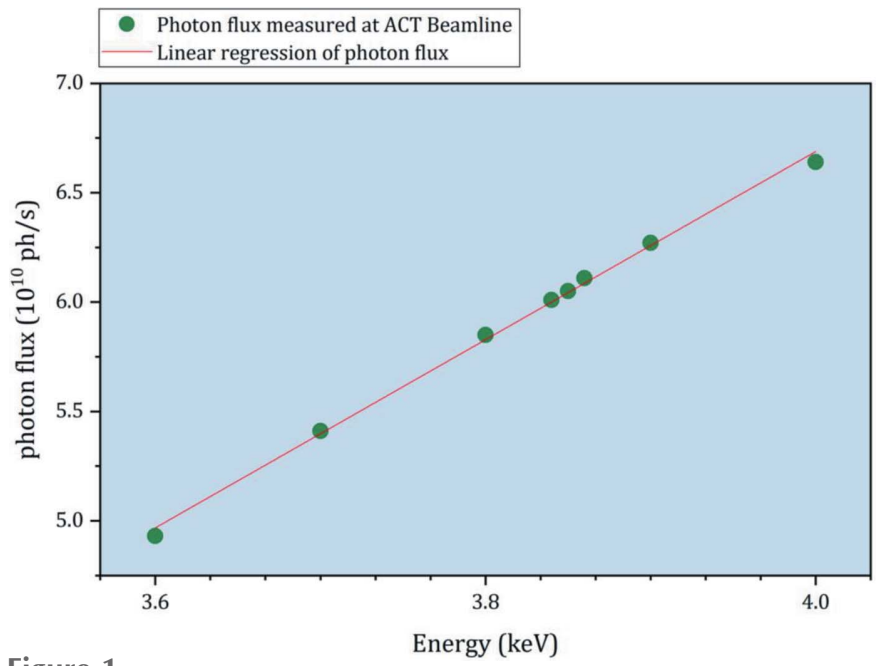

Figure 1

Energy $(\mathrm{keV})$

Current photon-flux conditions in the tender X-ray energy range at the ACT experiment. Synchrotron radiation beam path conditions from source to $I_{0}$ monitor (ionization chamber): $2.5 \mathrm{GeV}$ storage-ring electron energy, average electron-beam current $\simeq 120 \mathrm{~mA}, 2 \mathrm{~mm}(\mathrm{~h}) \times 1 \mathrm{~mm}(\mathrm{v})$ front-end (white beam) slit aperture, cylindrical collimating first $\mathrm{Si}$ mirror, $250 \mu \mathrm{m} \mathrm{Be}$ vacuum protection plus $100 \mu \mathrm{m}$ graphite thermalprotection window, $\mathrm{Si}\langle 111\rangle \mathrm{DCM}$ crystal pair, toroidal focusing second $\mathrm{Si}$ mirror, $25 \mu \mathrm{m}$ KAPTON window and synchrotron radiation beam spot size $\simeq 1 \mathrm{~mm} \times 1 \mathrm{~mm}$. detector high-voltage/power supply and signal lines, vacuum pump hose, etc.). A special access port based on a gear-stick sleeve at the front-side right-hand corner (in beam direction) of the box allows one to insert the supply lines for the modified $\mathrm{LN}_{2}$ cryostat, which are bundled in a flexible stainless-steel tube ( $c f$. Fig. 5, left image, and the detailed description below). The plexiglass box is further equipped with a large detachable lid sealed by a PVC gasket at the wall opposite from the crystal stage (right-hand side in beam direction). The large opening provides inside access for installation of the standard transmission/fluorescence XAFS detection equipment with ionization chambers (Poikat, Germany, positioned on X-95 rails) and an electrically cooled eight-element LEGe detector (Mirion, France, $c f$. Fig. 5, right image) or a Laue diffraction setup using X-ray sensitive storage screens (PerkinElmer, USA). In closed configuration at inert gas conditions, longsleeved gloves at various positions at all four side walls and the oriel allow one to handle sample cells and manipulate samples and equipment inside the box, including the exchange of analyzer-crystal sets.

Compared with the original setup described by Zimina et al. (2017), the improved design of the box enclosing the HR-XES setup offers the following advantages:

(i) The box remains permanently installed on top of the breadboard table, minimizing the time to switch between HRXES and standard X-ray absorption spectroscopy (XAS) experiments at ACT.

(ii) The front and back side walls of the box are fitted with ISO-KF 50 flange feedthroughs, simplifying switching between ACT and CAT stations by bridging the box with a vacuum pipe (possible without opening the box).

(iii) There is significantly improved He gas purity and correspondingly higher photon flux.

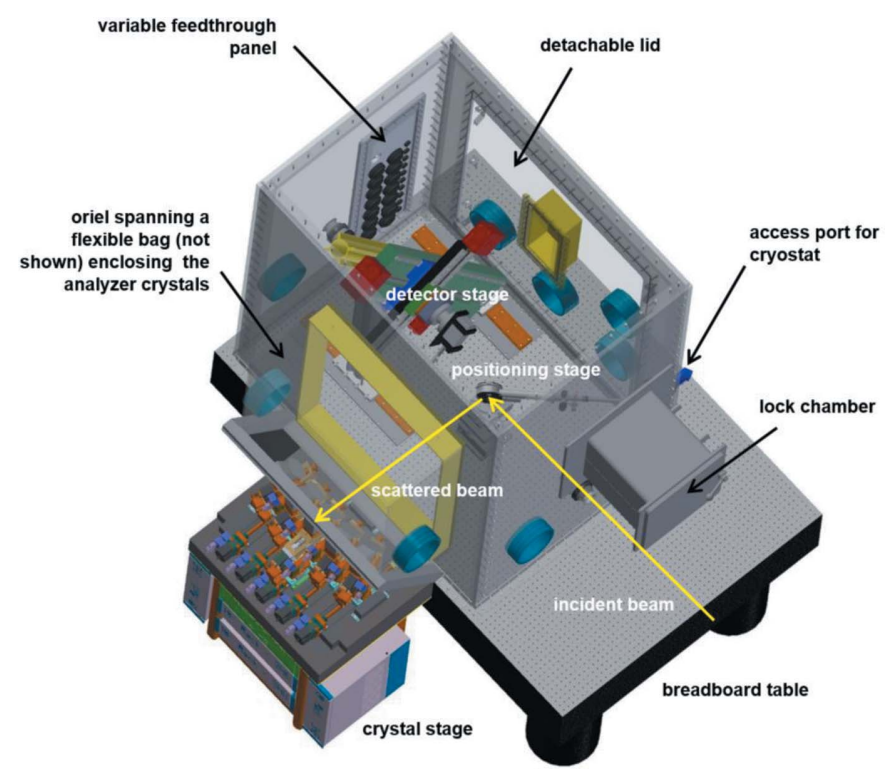

Figure 2

A 3D CAD model of the He box, providing an improved concept with possibilities for several experiments, e.g. enabling in situ measurements and cryostat experiments at the $M$-edges of actinides at the ACT station. 
(iv) There is significantly reduced $\mathrm{He}$ consumption during tender X-ray measurements.

(v) It has a large lock chamber, e.g. for transfer of in situ sample cells.

\section{Implementation of a liquid nitrogen flow-through cryostat for HR-XES measurements}

A commercial flow-through cryostat primarily developed for microscopy applications (Oxford Instruments MicrostatHe, UK) - optionally operational with $\mathrm{LHe}$ or $\mathrm{LN}_{2}$ as cryogenic coolant - was selected to be adapted to the HR-XES setup at ACT. It has been modified for tender X-ray (An $M$-edge) requirements while providing a special clamp mechanism enabling fast sample changes with the new cryo-sample cells. The instrument was chosen based on the special vacuumchamber dimensions offering a large solid-angle field of view ( $\sim 140^{\circ}$ opening angle) onto the sample(s) and a narrow gap of $\sim 2 \mathrm{~mm}$ between the sample surface and the outer vacuum window (as required, e.g. for cryo-microscopy investigations). This in turn allows the X-rays isotropically emitted from the sample to be captured and diffracted by all five analyzer

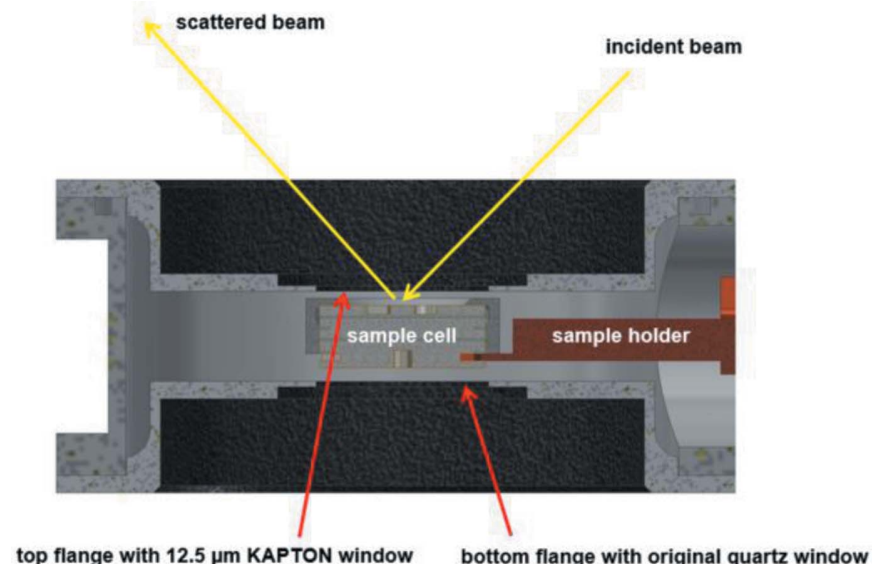

top flange with $12.5 \mu \mathrm{m}$ KAPTON window bottom flange with original quartz window

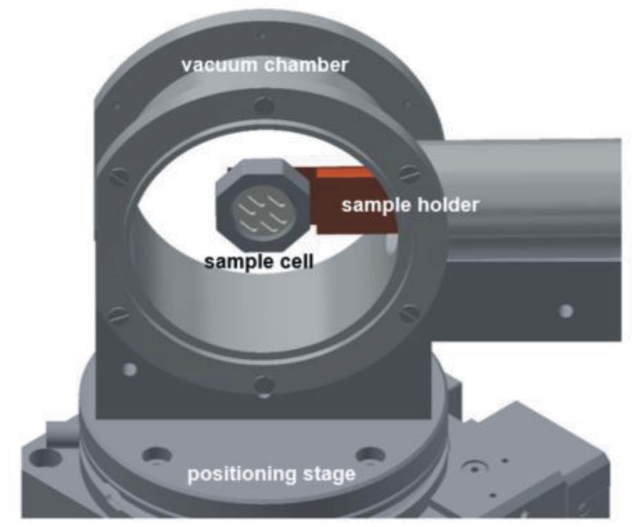

Figure 3

Top - a cross-section CAD drawing of the modified MicrostatHe vacuum chamber (side view). The original sample holder has been replaced by a copper fork clamping the sample cell, as described in Section 4. Bottom a $3 \mathrm{D}$ CAD drawing of the vacuum chamber with removed flanges mounted on top of the positioning stage, exhibiting the sample holder (copper fork) and sample cell assembly. crystals in the $1 \mathrm{~m}$ Rowland circle arrangement. The original cryostat sample holder - bolted to the heat-exchanger block with the liquid coolant circulating inside absorbing the thermal energy - was replaced by a copper fork with a slot clamping the actual sample cells (Fig. 3). The sample cell (Fig. 4) - adhering to the double containment rule for radioactive samples - consists of six stacked components (from bottom to top): the threaded anodized aluminium body with a groove for the copper fork and up to six elongated cavities milled into one side receiving different sample materials (solids/powders, wet pastes or liquids), a flat ring-shaped TEFLON gasket, an 8 or $12.5 \mu \mathrm{m}$ KAPTON (polyimide) disk, a second TEFLON gasket, a second KAPTON disk, and a brass cap nut with a large opening giving access to the sample cavities below the transparent KAPTON membranes. The nut is tightly screwed onto the cell body, pressing the stacked windows and gaskets against each other, the disk and the cap on top and thereby tightly encapsulating the radioactive materials. Extensive pumping tests exposing the sealed sample cell to the thermal-insulation vacuum (in the $10^{-5}$ mbar range) have been carried out with inactive dummy samples prior to initial experiments with radioactive materials. The loaded sample cells are pre-frozen in an $\mathrm{LN}_{2}$ bath and introduced via the lock chamber into the dry He atmosphere inside the box. The cylindrical cryostat chamber is opened at cryogenic temperatures and the sample cell is attached to the copper fork. The original quartz window of the sample chamber flange facing the top side of the sample cell has been replaced by an epoxy-glued $12.5 \mu \mathrm{m}$ KAPTON disk. Although already absorbing $\sim 35 \%$ of the photon intensity at the $\mathrm{Np} M_{5}$-edge energy $\left[E \mathrm{~Np}\left(3 d_{5 / 2}\right) \simeq 3664 \mathrm{eV}, E \mathrm{~Np}\left(M_{\alpha 1}\right) \simeq 3261 \mathrm{eV}\right]$, the cryostat window thickness has been a necessary compromise between vacuum stability and X-ray transparency. The vacuum chamber attached to the flexible tube containing the $\mathrm{LN}_{2}$ supply and exhaust lines, as well as thermal sensor (PT100 type) and heater connections, is mounted by a half-shell adapter on top of the sample positioning stage at $45^{\circ}$ relative to the impinging beam (Fig. 5, left image). The sample $x-/ y-/ z$ -
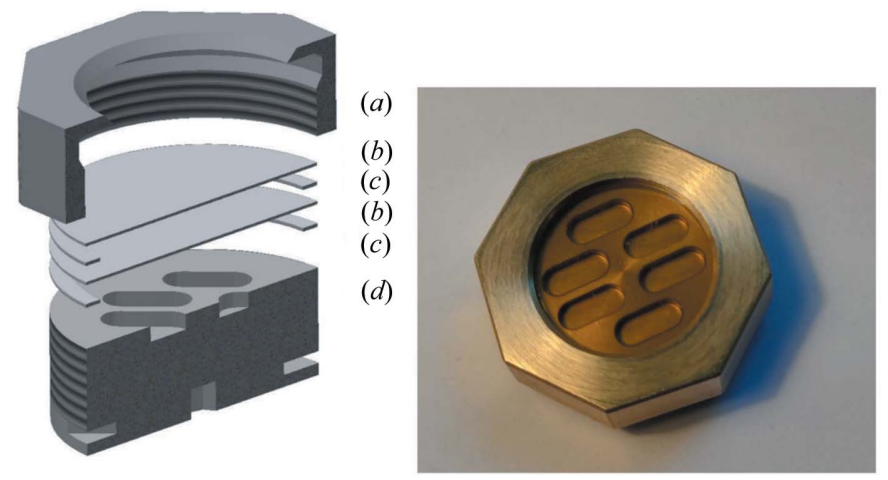

Figure 4

Left image - an exploded-view 3D CAD drawing of the sample cell assembly. From top to bottom: (a) cap nut, (b) KAPTON disk, (c) TEFLON gasket, $(b)$ KAPTON disk, $(c)$ TEFLON gasket, $(d)$ cell body. Right image - a top view of a sealed sample cell with six sample cavities (outer diameter $\simeq 30 \mathrm{~mm}$ ). 


\section{actinide physics and chemistry}
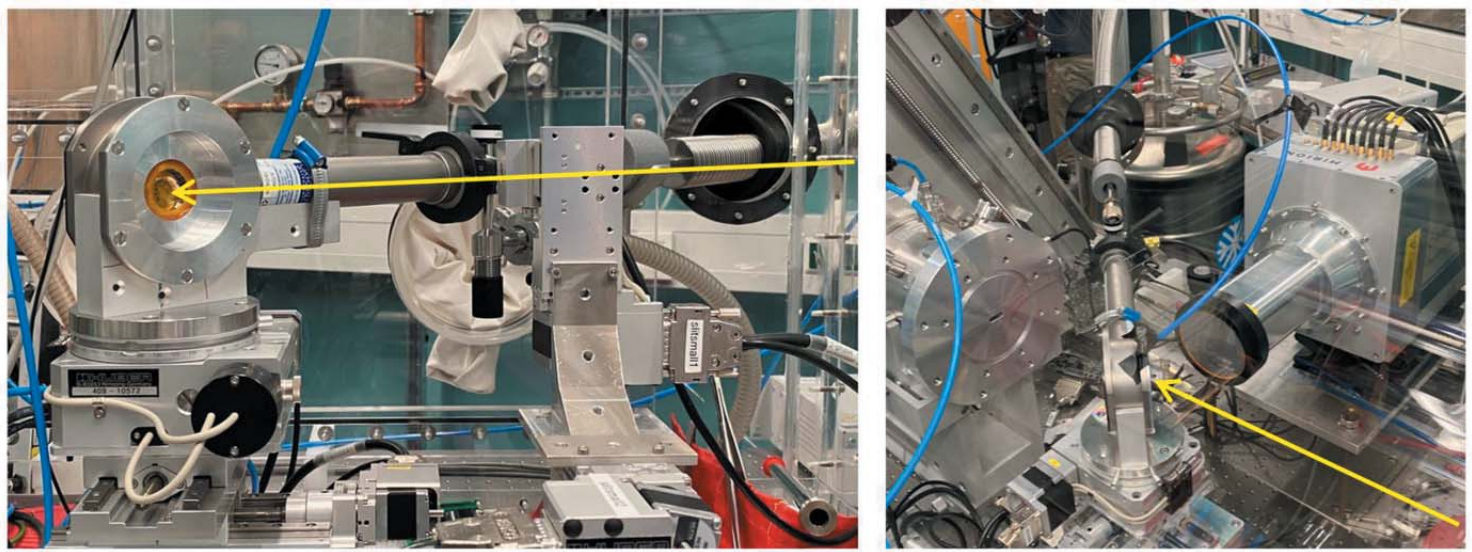

Figure 5

Left image - the cryostat vacuum chamber rigidly mounted on top of the sample positioning stage (analyzer-crystal point of view). The sample cell is visible through the outer KAPTON vacuum window. The arrow marks the incoming beam passing the auxiliary four-blade slit in front of the sample. Right image - the cryostat used inside the He box with opened lid for standard fluorescence XAFS detection mode. The arrow marks the incoming beam.

position is precisely adjusted by a set of crossed alignment lasers. A modified sample cell was fitted with a second PT-100 sensor to measure the temperature directly at one of the sample cavities. This setup enabled a sample temperature of $141.2 \pm 1.5 \mathrm{~K}$ at irradiation conditions with the heat-exchange block cooled down and stabilized at $\mathrm{LN}_{2}$ temperature ( $\sim 77 \mathrm{~K})$. So far no attempts to operate the cryostat equipment with liquid $\mathrm{He}$ as coolant have been made. Future design modifications aim at improving the thermal contact between sample cell and clamping mechanism.

\section{Np $M_{5}$-edge HR-XANES measurements at low concentrations and cryogenic conditions}

As already mentioned above, oxidation-state changes of redox-sensitive An elements [primarily $\mathrm{U}, \mathrm{Np}$ and $\mathrm{Pu}$, which may exist (or even co-exist) at different oxidation states (IVVI) at the relevant geochemical conditions] are not exclusively induced by redox partners such as $\mathrm{Fe}(\mathrm{II})$ in mineral surface reactions. These changes have been observed to occur for mostly wet samples in XAS-based speciation experiments under inert gas conditions. It is suspected that water radicals formed in bright X-ray beams might interact with the An cations and change their oxidation state. Another conjecture is effects due to increased sample temperatures at X-ray irradiation conditions. As an example to illustrate the performance of our improved tender X-ray emission spectroscopy setup, we present $\mathrm{Np} M_{5}$-edge HR-XANES results in relation to our recent study on the interaction mechanisms of ${ }^{237} \mathrm{~Np}-\mathrm{a}$ long-lived $\alpha$-emitting isotope generated during operation of nuclear fission reactors - with clay minerals, which are highly relevant sorbents in the multi-barrier concept for nuclearwaste disposal in deep-geological formations. In this context, illite is considered as an important mineral fraction of several clay formations discussed as potential host rocks. Details on the successful measurement of low Np concentrations on illite are currently under revision in a previously submitted article (Schacherl et al., 2021). Therein, experiments at conditions expected to prevail in the far field of a breached disposal site, i.e. low $\mathrm{Np}(\mathrm{IV} / \mathrm{V})$ concentrations down to 1 p.p.m., are described in order to verify the lowest possible Np loadings on clay surfaces for which Np speciation using the HR-XANES technique is still possible. Moreover, in order to suppress radiation-induced changes, the samples in our $\mathrm{Np} M_{5}$-edge HR-XANES experiments were cooled down to $141.2 \pm 1.5 \mathrm{~K}$ using the setup described above. These results were subsequently compared with room-temperature measurements.

An Illite du Puy (6.94\% $\mathrm{Fe}_{2} \mathrm{O}_{3}$ ) (Montoya et al., 2018) sample was contacted with $\mathrm{Np}$ at an initial concentration of $c_{0}[\mathrm{~Np}(\mathrm{~V})]=1 \times 10^{-6} \mathrm{~mol} \mathrm{l}^{-1}$ for 11 days at $\mathrm{pH} 9.2$ with a solid-to-liquid ratio of $2 \mathrm{~g} \mathrm{l}^{-1}$ and $I=0.1 \mathrm{~mol} \mathrm{l}^{-1} \mathrm{NaCl}$, resulting in a sorbed Np loading on illite of $83 \pm 2$ p.p.m. The sample preparation procedure is as well described in detail by Schacherl et al. (2021). After centrifugation at $15000 \mathrm{r} \mathrm{min}^{-1}$ for $80 \mathrm{~min}$ (LLG-uniCFUGE 5, Lab Logistics Group GmbH, Germany), the wet illite paste was transferred to the cryostat sample cell in an intert gas (Ar) glove box and encapsulated by two $8 \mu \mathrm{m}$ KAPTON layers (polyimide film, Advent Research Materials, United Kingdom). The sealed sample cell was checked for the absence of surface contamination and transferred to the beamline inside a gastight transport container. At the ACT station the sample cell was pre-frozen in a liquid nitrogen bath and subsequently mounted at the sample holder inside the $\mathrm{He}$ box as described in Section 4.

A solid Np reference sample $\left\{\mathrm{K}_{3} \mathrm{Na}\left[\mathrm{U}, \mathrm{NpO}_{2}\left(\mathrm{CO}_{3}\right)_{3}\right] \times \mathrm{H}_{2} \mathrm{O}\right.$ (Vitova et al., 2020)\} was used to calibrate the DCM for $\mathrm{Np}$ $M_{5}$-edge HR-XANES spectroscopy. The maximum of the most intense absorption resonance ('white line') of this sample was assigned to $3664 \mathrm{eV}$. The $\mathrm{Np} M \alpha_{1}$ fluorescence line was recorded with four $\mathrm{Si}\langle 220\rangle$ analyser crystals, aligned at a Bragg angle of $81.92^{\circ}$. An energy range from 3658 to $3674 \mathrm{eV}$ with a step size of $0.2 \mathrm{eV}$ across the edge $(3660-3666 \mathrm{eV})$ and $0.4 \mathrm{eV}$ in the pre- and post-edge region was scanned for every spectrum. For the sample at room temperature, $9 \times 10$ min scans were recorded. For the sample mounted inside the cryostat at $141.2 \pm 1.5 \mathrm{~K}, 9 \times 15 \mathrm{~min}$ scans were recorded. The program 
OriginPro (OriginLab, 2018) was used to calibrate the spectra using the reference scans recorded before and after each sample scan.

The higher photon flux achieved with the advanced He box setup, further optimization of the beamline optics alignment and recent improvements of the KARA storage ring operation have led to the observation of beam-induced alterations in hydrated samples such as wet Np-sorbed illite pastes. This is clearly shown in Fig. 6(a), where the average of several $\mathrm{Np}$ $M_{5}$-edge HR-XANES scans of the Np/illite sample with the progression of irradiation time of a series of measurements performed at room temperature on the same sample spot are depicted. Peak $B$ - significant for the presence of $\mathrm{Np}(\mathrm{V})$ 'neptunyl' species (Vitova et al., 2020) - disappears after prolonged irradiation time, strongly suggesting reduction of $\mathrm{Np}(\mathrm{V})$ to $\mathrm{Np}(\mathrm{IV})$. The 'white line' maximum (peak $A$ ) position does not significantly change upon reduction of $\mathrm{Np}(\mathrm{V})$
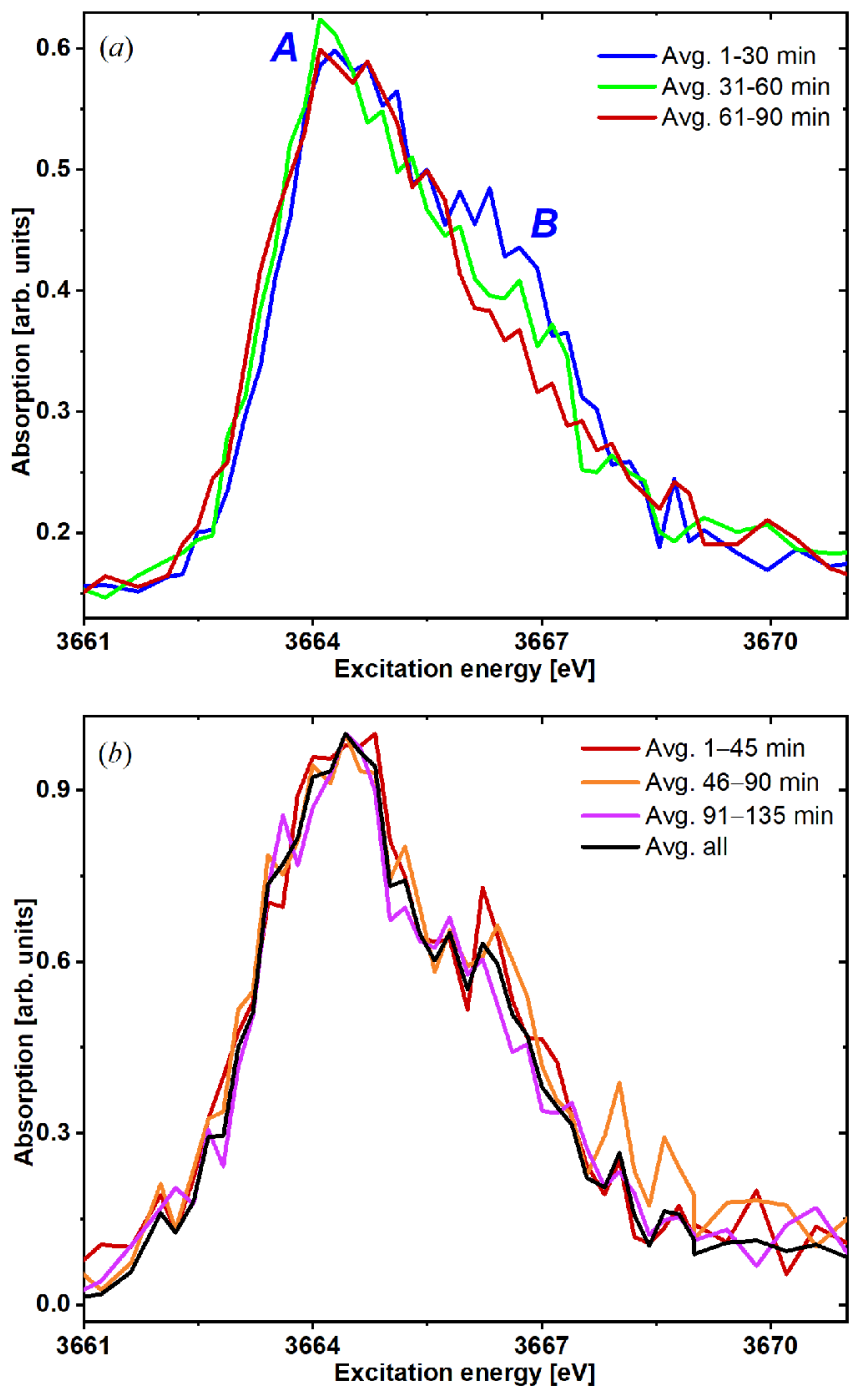

Figure 6

(a) Gradual change of Np $M_{5}$-edge HR-XANES spectra of a sample with $83 \pm 2$ p.p.m. Np sorbed on illite ( $c f$. Section 6 for sample details) at 300.0 $\pm 1.5 \mathrm{~K}$. Changes in the shoulder denoted as feature B are visible with irradiation time. $(b)$ At cryogenic conditions $(141.2 \pm 1.5 \mathrm{~K})$, no significant changes of the spectra are discernible within the noise level. to $\mathrm{Np}(\mathrm{IV})$ - a well known anomaly for pentavalent 'actinyl' species upon the loss of the trans-dioxo conformation upon transition to the tetravalent state (Vitova et al., 2015, 2017, 2018, 2020; Podkovyrina et al., 2016).

In contrast to that, it becomes clearly evident from the comparison of scans averaged for different time intervals, as depicted in Fig. 6(b), that beam-induced reduction is successfully suppressed when applying the cryostat setup stabilizing a sample temperature of $141.2 \pm 1.5 \mathrm{~K}$. Within the noise level, no significant changes in the spectra were detected when irradiating the same spot for up to more than $130 \mathrm{~min}$.

\section{Outlook}

Several technical upgrades and extensions at the ACT station are foreseen to be realized in the near future. Some of them have been already specified and are in the state of procurement:

(1) A single-element SDD (Hitachi Vortex-EX60, USA) will be added to the detector pool to allow for standard (total) fluorescence-yield XAFS spectra recorded parallel to the HR-XANES measurements. This device will facilitate the precise localization of sample coordinates in the case of multiple-position sample holders, e.g. the cryo-cells described in Section 4.

(2) The flexible reusable storage phosphor screens used so far for Laue-type diffraction (WAXS/HEXS) experiments ( $c f$. e.g. Bouty et al., 2021) read out by a laser scanner (PerkinElmer Cyclone Plus, USA) following each exposure - a timeconsuming procedure preventing the investigation of dynamic processes - will be replaced by an X-ray camera with a large active area (164 mm-diameter fluorescence screen) with a tapered waveguide (Photonic Science sCMOS_37MP, United Kingdom).

(3) Based on the excellent performance at INE-Beamline, a new set of mono- and poly-capillary X-ray lenses (Helmut Fischer GmbH, Germany), covering the tender to hard X-ray range, has been ordered to collimate or focus the impinging X-rays, increasing angular resolution and flux density for Laue-type diffraction measurements as well as enabling spatially resolved $\mu$-XAFS/XRF (optionally in confocal detection mode) and $\mu$-HR-XANES measurements with spot sizes down to $10 \mu \mathrm{m}$ (FWHM). The capillary optics will be positioned and precisely aligned in the beam using a hexapod microrobot (Physik Instrumente H-811, Germany).

Five years after its initial commissioning, the ACT station at the CAT-ACT wiggler beamline has been developed into a unique X-ray spectroscopy station for the investigation of various radionuclide materials with state-of-the-art speciation techniques - strongly focusing on 'flux hungry' photon-in/ photon-out techniques. The outlined modifications and improvements will even increase the high flexibility and sensitivity in the near future. The ACT station - although officially situated at a KIT in-house large-scale research facility - may be accessed by external users through direct cooperation with KIT-INE (https://www.ine.kit.edu). 


\section{Acknowledgements}

The authors would like to thank A. Gensch for the help with technical drawings and conceptual designs. We also gratefully acknowledge the KIT Light Source for provision of beam time at the ACT station operated by KIT-INE and would like to thank the Institute for Beam Physics and Technology (KITIBPT) for operation of KARA.

\section{Funding information}

This project has received funding from the European Union's Horizon 2020 research and innovation program under grant agreement No. 847593. The Federal Ministry of Education and Research (BMBF) and the Helmholtz Association of German Research Centres (HGF) are acknowledged for funding within the HOVER project. We acknowledge the HGF as well for the VH-NG-734 grant. We also acknowledge funding from the ERC Consolidator Grant 2020 under the European Union's Horizon 2020 research and innovation programme (grant agreement No. 101003292).

\section{References}

Amidani, L., Vaughan, G. B. M., Plakhova, T. V., Romanchuk, A. Y., Gerber, E., Svetogorov, R., Weiss, S., Joly, Y., Kalmykov, S. N. \& Kvashnina, K. O. (2021). Chem. A Eur. J. 27, 252-263.

Bahl, S., Peuget, S., Pidchenko, I., Pruessmann, T., Rothe, J., Dardenne, K., Delrieu, J., Fellhauer, D., Jégou, C., Geckeis, H. \& Vitova, T. (2017). Inorg. Chem. 56, 13982-13990.

Bao, H., Duan, P., Zhou, J., Cao, H., Li, J., Yu, H., Jiang, Z., Liu, H., Zhang, L., Lin, J., Chen, N., Lin, X., Liu, Y., Huang, Y. \& Wang, J. Q. (2018). Inorg. Chem. 57, 11404-11413.

Böhler, R., Welland, M. J., Prieur, D., Cakir, P., Vitova, T., Pruessmann, T., Pidchenko, I., Hennig, C., Guéneau, C., Konings, R. J. M. \& Manara, D. (2014). J. Nucl. Mater. 448, 330-339.

Booth, C. H., Jiang, Y., Wang, D. L., Mitchell, J. N., Tobash, P. H., Bauer, E. D., Wall, M. A., Allen, P. G., Sokaras, D., Nordlund, D., Weng, T. C., Torrez, M. A. \& Sarrao, J. L. (2012). Proc. Natl Acad. Sci. USA, 109, 10205-10209.

Booth, C. H., Medling, S. A., Jiang, Y., Bauer, E. D., Tobash, P. H., Mitchell, J. N., Veirs, D. K., Wall, M. A., Allen, P. G., Kas, J. J., Sokaras, D., Nordlund, D. \& Weng, T. C. (2014). J. Electron Spectrosc. Relat. Phenom. 194, 57-65.

Bouty, O., Ramond, L., Dardenne, K. \& Rothe, J. (2021). J. Synchrotron Rad. 28, 214-223.

Butorin, S. M., Mancini, D. C., Guo, J. H., Wassdahl, N., Nordgren, J., Nakazawa, M., Tanaka, S., Uozumi, T., Kotani, A., Ma, Y., Myano, K. E., Karlin, B. A. \& Shuh, D. K. (1996). Phys. Rev. Lett. 77, 574-577.

Butorin, S. M., Modin, A., Vegelius, J. R., Suzuki, M. T., Oppeneer, P. M., Andersson, D. A. \& Shuh, D. K. (2016). Anal. Chem. 88, 4169-4173.

Butorin, S. M., Shuh, D. K., Kvashnina, K. O., Guo, J., Werme, L. \& Nordgren, J. (2013). Anal. Chem. 85, 11196-11200.

Dalodière, E., Virot, M., Morosini, V., Chave, T., Dumas, T., Hennig, C., Wiss, T., Dieste Blanco, O., Shuh, D. K., Tyliszcak, T., Venault, L., Moisy, P. \& Nikitenko, S. I. (2017). Sci. Rep. 7, 43514.

Denecke, M. A., Dardenne, K. \& Marquardt, C. M. (2005). Talanta, 65, 1008-1014.

Ditter, A. S., Holden, W. M., Cary, S. K., Mocko, V., Latimer, M. J., Nelson, E. J., Kozimor, S. A. \& Seidler, G. T. (2020). J. Synchrotron Rad. 27, 446-454.

Duan, P., Gu, S., Cao, H., Li, J. \& Huang, Y. (2017). X-ray Spectrom. 46, 12-18.
Duan, P. Q., Bao, H. L., Li, J., Cao, H. J. \& Huang, Y. Y. (2017). Nucl. Sci. Tech. 28, 2.

Epifano, E., Naji, M., Manara, D., Scheinost, A. C., Hennig, C., Lechelle, J., Konings, R. J. M., Guéneau, C., Prieur, D., Vitova, T., Dardenne, K., Rothe, J. \& Martin, P. M. (2019). Commun. Chem. 2, 59 .

Gerber, E., Romanchuk, A. Y., Pidchenko, I., Amidani, L., Rossberg, A., Hennig, C., Vaughan, G. B. M., Trigub, A., Egorova, T., Bauters, S., Plakhova, T., Hunault, M. O. J. Y., Weiss, S., Butorin, S. M., Scheinost, A. C., Kalmykov, S. N. \& Kvashnina, K. O. (2020). Nanoscale, 12, 18039-18048.

Göttlicher, J., Steininger, R., Mangold, S., Spangenberg, T., Veselska, V., Eiche, E., Schneider, M., Neumann, T., Penkert, G. \& Penkert, P. (2018). 17th International Conference on X-ray Absorption Fine Structure, 22-27 July 2018, Krakau, Poland.

Grolimund, D. (2021). Personal communication.

Heathman, S., Rueff, J. P., Simonelli, L., Denecke, M. A., Griveau, J. C., Caciuffo, R. \& Lander, G. H. (2010). Phys. Rev. B, 82, 201103.

Honda, F., Kawamura, N., Li, D., Hirose, Y., Homma, Y., Nakamura, A., Shimizu, Y., Maurya, A., Sato, Y. J. \& Aoki, D. (2020). JPS Conf. Proc. 29, 013002.

Hudry, D., Apostolidis, C., Walter, O., Janssen, A., Manara, D., Griveau, J. C., Colineau, E., Vitova, T., Prüssmann, T., Wang, D., Kübel, C. \& Meyer, D. (2014). Chem. Eur. J. 20, 10431-10438.

Hunault, M. O. J. Y., Lelong, G., Cormier, L., Galoisy, L., Solari, P.-L. \& Calas, G. (2019). Inorg. Chem. 58, 6858-6865.

Jin, G. B., Malliakas, C. D., Hu, Y., Booth, C. H., Ibers, J. A., Sokaras, D., Weng, T., Skanthakumar, S. \& Soderholm, L. (2019). Angew. Chem. Int. Ed. 58, 16130-16133.

Kawamura, N., Hirose, Y., Honda, F., Shimokasa, R., Ishimatsu, N., Mizumaki, M., Kawaguchi, S. I., Hirao, N. \& Mimura, K. (2020). JPS Conf. Proc. 30, 011172.

Kvashnina, K. O., Butorin, S. M., Martin, P. \& Glatzel, P. (2013). Phys. Rev. Lett. 111, 1-5.

Kvashnina, K. O., Romanchuk, A. Y., Pidchenko, I., Amidani, L., Gerber, E., Trigub, A., Rossberg, A., Weiss, S., Popa, K., Walter, O., Caciuffo, R., Scheinost, A. C., Butorin, S. M. \& Kalmykov, S. N. (2019). Angew. Chem. Int. Ed. 58, 17558-17562.

Manley, M. E., Jeffries, J. R., Said, A. H., Marianetti, C. A., Cynn, H., Leu, B. M. \& Wall, M. A. (2012). Phys. Rev. B, 85, 132301.

Manley, M. E., Said, A. H., Fluss, M. J., Wall, M., Lashley, J. C., Alatas, A., Moore, K. T. \& Shvyd'ko, Y. (2009). Phys. Rev. B, 79, 052301.

Modin, A., Yun, Y., Suzuki, M. T., Vegelius, J., Werme, L., Nordgren, J., Oppeneer, P. M. \& Butorin, S. M. (2011). Phys. Rev. B, 83, 075113.

Montoya, V., Baeyens, B., Glaus, M. A., Kupcik, T., Marques Fernandes, M., Van Laer, L., Bruggeman, C., Maes, N. \& Schäfer, T. (2018). Geochim. Cosmochim. Acta, 223, 1-20.

OriginLab (2018). OriginPro. OriginLab Corporation, Northampton, Massachusetts, USA.

Pan, Z., Bártová, B., LaGrange, T., Butorin, S. M., Hyatt, N. C., Stennett, M. C., Kvashnina, K. O. \& Bernier-Latmani, R. (2020). Nat. Commun. 11, 4001.

Pidchenko, I., März, J., Hunault, M. O. J. Y., Bauters, S., Butorin, S. M. \& Kvashnina, K. O. (2020). Inorg. Chem. 59, 11889-11893.

Podkovyrina, Y., Pidchenko, I., Prüßmann, T., Bahl, S., Göttlicher, J., Soldatov, A. \& Vitova, T. (2016). J. Phys. Conf. Ser. 712, 012092.

Popa, K., Prieur, D., Manara, D., Naji, M., Vigier, J.-F., Martin, P. M., Dieste Blanco, O., Scheinost, A. C., Prüßmann, T., Vitova, T., Raison, P. E., Somers, J. \& Konings, R. J. M. (2016). Dalton Trans. 45, 7847-7855.

Popa, K., Raison, P. E., Martel, L., Martin, P. M., Prieur, D., Solari, P. L., Bouëxière, D., Konings, R. J. M. \& Somers, J. (2015). J. Solid State Chem. 230, 169-174.

Prüßmann, T. (2016). PhD thesis, Karlsruhe Institute for Technology, Germany.

Rothe, J., Altmaier, M., Dagan, R., Dardenne, K., Fellhauer, D., Gaona, X., Corrales, E. G.-R., Herm, M., Kvashnina, K. O., Metz, 
V., Pidchenko, I., Schild, D., Vitova, T. \& Geckeis, H. (2019). Geosciences, 9, 91.

Rothe, J., Butorin, S., Dardenne, K., Denecke, M. A., Kienzler, B., Löble, M., Metz, V., Seibert, A., Steppert, M., Vitova, T., Walther, C. \& Geckeis, H. (2012). Rev. Sci. Instrum. 83, 043105.

Rueff, J. P., Raymond, S., Yaresko, A., Braithwaite, D., Leininger, P., Vankó, G., Huxley, A., Rebizant, J. \& Sato, N. (2007). Phys. Rev. B, 76, 085113 .

Schacherl, B., Joseph, C., Lavrova, P., Beck, A., Reitz, C., Prüssmann, T., Fellhauer, D., Lee, J.-Y., Dardenne, K., Rothe, J., Geckeis, H. \& Vitova, T. (2021). Anal. Chim. Acta. Submitted.

Scheinost, A. C., Claussner, J., Exner, J., Feig, M., Findeisen, S., Hennig, C., Kvashnina, K. O., Naudet, D., Prieur, D., Rossberg, A., Schmidt, M., Qiu, C., Colomp, P., Cohen, C., Dettona, E., Dyadkin, V. \& Stumpf, T. (2021). J. Synchrotron Rad. 28, 333-349.

Szlachetko, J., Nachtegaal, M., De Boni, E., Willimann, M., Safonova, O., Sa, J., Smolentsev, G., Szlachetko, M., Van Bokhoven, J. A., Dousse, J. C., Hoszowska, J., Kayser, Y., Jagodzinski, P., Bergamaschi, A., Schmitt, B., David, C. \& Lücke, A. (2012). Rev. Sci. Instrum. 83, 103105.

Tobin, J. G., Arena, D. A., Chung, B., Roussel, P., Terry, Schulze, R. K., Farr, J. D., Zocco, T., Heinzelman, K., Rotenberg, E. \& Shuh, D. K. (2002). J. Nucl. Sci. Technol. 39, 98-101.

Tobin, J. G. \& Shuh, D. K. (2015). J. Electron Spectrosc. Relat. Phenom. 205, 83-91.
Vitova, T., Denecke, M. A., Göttlicher, J., Jorissen, K., Kas, J. J., Kvashnina, K., Prüßmann, T., Rehr, J. J. \& Rothe, J. (2013). J. Phys. Conf. Ser. 430, 012117.

Vitova, T., Green, J. C., Denning, R. G., Löble, M., Kvashnina, K., Kas, J. J., Jorissen, K., Rehr, J. J., Malcherek, T. \& Denecke, M. A. (2015). Inorg. Chem. 54, 174-182.

Vitova, T., Kvashnina, K. O., Nocton, G., Sukharina, G., Denecke, M. A., Butorin, S. M., Mazzanti, M., Caciuffo, R., Soldatov, A., Behrends, T. \& Geckeis, H. (2010). Phys. Rev. B, 82, 235118.

Vitova, T., Pidchenko, I., Biswas, S., Beridze, G., Dunne, P. W., Schild, D., Wang, Z., Kowalski, P. M. \& Baker, R. J. (2018). Inorg. Chem. 57, 1735-1743.

Vitova, T., Pidchenko, I., Fellhauer, D., Bagus, P. S., Joly, Y., Pruessmann, T., Bahl, S., Gonzalez-Robles, E., Rothe, J., Altmaier, M., Denecke, M. A. \& Geckeis, H. (2017). Nat. Commun. 8, 16053.

Vitova, T., Pidchenko, I., Schild, D., Prüßmann, T., Montoya, V., Fellhauer, D., Gaona, X., Bohnert, E., Rothe, J., Baker, R. J. \& Geckeis, H. (2020). Inorg. Chem. 59, 8-22.

Walshe, A., Prüßmann, T., Vitova, T. \& Baker, R. J. (2014). Dalton Trans. 43, 4400-4407.

Wilk, P. A., Shaughnessy, D. A., Wilson, R. E. \& Nitsche, H. (2005). Environ. Sci. Technol. 39, 2608-2615.

Zimina, A., Dardenne, K., Denecke, M. A., Doronkin, D. E., Huttel, E., Lichtenberg, H., Mangold, S., Prüßmann, T., Rothe, J., Spangenberg, T., Steininger, R., Vitova, T., Geckeis, H. \& Grunwaldt, J.-D. (2017). Rev. Sci. Instrum. 88, 113113. 